\title{
Who Would Pay for Facebook? Self Esteem as a Predictor of User Behavior, Identity Construction and Valuation of Virtual Possessions
}

\author{
Jiaqi $\mathrm{Nie}^{1,2}$ and S. Shyam Sundar ${ }^{2,3}$ \\ ${ }^{1}$ Keio-NUS CUTE Center, Interactive \& Digital Media Institute, \\ National University of Singapore, 119613, Singapore \\ nicol018nie@gmail.com \\ ${ }^{2}$ Department of Interaction Science, Sungkyunkwan University, Seoul, Korea \\ ${ }^{3}$ Media Effects Research Laboratory, Penn State University, University Park, PA, USA \\ sss12@psu.edu
}

\begin{abstract}
Self-presentation is a major preoccupation in Facebook. Users carefully construct their online profile and assiduously edit postings on their wall in order to strategically shape their online persona. This study examines some psychological antecedents and consequences of such actions. In particular, we propose that users' self-esteem affects their sense of agency and self-monitoring tendencies, with the former leading to a fuller description of their profile and the latter contributing to more frequent customization of their wall. In turn, these behaviors are hypothesized to contribute to users' personal and social identity respectively, en route to affecting their valuation of Facebook as a virtual possession. Structural equation modeling analysis of survey data $(N=221)$ largely supports this model and reveals that the personal identity reflected in one's Facebook account is a major predictor of the degree to which one values it as a possession. We discuss the implications of "I" vs. "Me" in self-esteem with regard to virtual possessions in social networking environments.
\end{abstract}

Keywords: self-esteem, Facebook activity, online identity construction, virtual possession, survey, quantitative methods, structural equation modeling (SEM).

\section{Introduction}

It is natural for humans to view the self as being situated in a social experience. Individuals construct their identity by carefully articulating their personality and paying close attention to how they present themselves to others. With the arrival of networked media, this articulation becomes even more pronounced. Internet users, particularly those who have social media accounts, must now consider their online personas in addition to-or as part of - their real-life identities. It has been well recognized by scholars that the Internet is challenging and shaping one's identity [1-3]. In fact, many studies have identified effects of Internet use on individual identity. Research has focused on the changes in self-concept ushered in by the Internet, giving 
rise to the notion of "second self" as an online extension of one's psychological and social self [4], leading to a conscious accumulation of "virtual possessions" [5], such as digital images, music files and even the number of contacts on one's social networking site.

All this suggests that while the psychology of one's offline self may predict our online activities related to shaping our online self, these activities in turn would likely dictate the degree to which we define ourselves based on our online self and the extent to which we value our virtual possessions. An understanding of the psychological mechanisms involved in the translation of one's self concept to one's online identity can be quite insightful in enhancing our theoretical understanding of user motivations for specific activities in social media sites. It also has practical implications for the valuation of such sites (e.g., how much users of social networking sites would be willing to pay for the service if it were not free) and the design of identity-enhancing features that would maximize the value of virtual possessions for users.

We begin with a review of the theoretical framework underlying self-concept by focusing on the two facets of "Me" and "I" based on Mead's theory, and propose a series of hypotheses involving psychological concepts as well as user behaviors and attitudes pertaining to Facebook, the popular social networking site [6]. The model emerging from these hypotheses is then tested using structural equation modeling analysis, followed by a discussion of the specific associations discovered in the study and their implications for theory and practice.

\section{Literature Review}

\subsection{Mead's "I" \& "Me” in Self-esteem}

Several decades before the advent of social media, G.H. Mead [7] developed a systematic theory of the social nature of self by introducing the concepts of the "I" and "Me." According to this theory, individuals construct the "I" and the "Me" based on personal selfhood [6]. From a perspective of the world which can be reinterpreted by our actions and the feedback we receive, there are, on the one side, individuals who care about the "I" in selfhood, trying to know themselves by observing their own behaviors; on the other hand, the "Me" in one's self-concept is focused on what is learned in the interaction with others, and more generally with the environment.

Individuals' specific views about selfhood and the way they frame these views identify and contribute to their global self-esteem [8]. Individuals who see positive self-views from their own behavior are especially likely to be high in self-esteem. On the other hand, individuals who derive self-views from their interactions with others and the environment tend to be low in self-esteem.

Self-esteem lies at the core of one's self-concept and serves as the starting point for our examination of user identity in social media. Insofar as this study is concerned, 'self-esteem' refers to the evaluation of oneself, which is conceived both as a trait and a state of being [9]. We adopt the term 'self-esteem' to depict an individual's selfhood from a broad perspective, as proposed by Campbell et al. [10]. People with high 
self-esteem are consistent and clear about themselves, with the "I" dominating in one's persona; whereas people with low self-esteem tend to be confused about their self concept and feel anxious about self-relevant images in public; their character is strongly influenced and controlled by "Me" rather than "I" [11-13].

More broadly, the twin aspects of "I" and "Me," generated by high and low selfesteem respectively, are likely to lead to two different paths in influencing our online attitudes and behaviors, shaping our online identity, and eventually changing our valuation of our virtual possessions, as discussed in the sections that follow.

\subsection{Psychological Factors and Behaviors Based on Self-esteem}

There is consensus among scholars that self-esteem shapes the way we perceive ourselves and the strategies we use to present ourselves. On the one hand, self-esteem could be a proxy for the psychological sense of agency. Individuals who score high on self-esteem have a higher sense of self-control and enhanced initiative [11]. Higher self-esteem refers to a more favorable evaluation of oneself, which has profound consequences for one's "sense of agency" [14]. The term "sense of agency" is used to describe the "sense that I am the one who is causing or generating an action" ([15], p.15). Therefore, we hypothesize:

H1: The higher the level of self-esteem, the higher the degree of sense of agency.

On the other hand, when it is low, self-esteem is related to self-monitoring in public presentations. The need for impression management and self-monitoring is critical when those with low self-esteem express themselves publicly in SNS [16]. Empirically, social media researchers adopt self-esteem, an overall affective psychosocial development measure, in evaluating one's self or personality, to observe virtual selfhood in social networking sites like Facebook. For example, individuals with lower self-esteem have been shown to experience a higher level of bridging social capital by increasing their intensity of Facebook usage, measured in terms of the customization behaviors on one's Facebook wall [17]. This demonstrates the "Me" aspect of selfconcept, a tendency to monitor oneself constantly and rely on others for boosting one's self-esteem. Thus, we propose that:

$\mathrm{H} 2$ : The lower the level of self-esteem, the higher the level of self-monitoring.

According to Mead's social behaviorism [6], "individuals become aware of and learn to guide their behavior" during their process in defining and studying the idea of the self (as cited in [18], p. 165). In other words, individuals adjust their behaviors and shape their images available to others based on their view of themselves [19]. Facebook enables its users to communicate with a diverse set of affordances ("action possibilities"), such as posting comments, sharing pictures, and liking or highlighting contents [20]. This is specifically true after Facebook released its timeline version, which offers users more self-monitoring options on their Facebook wall. Therefore, we can expect users with low levels of self-esteem to be overly conscious of their wall and proceed to use the available customization options, such as editing certain pictures, removing tags and deleting comments. On the other hand, the profile space in Facebook is a key location for self-presentation that can help boost one's sense of agency. Online SNS profiles are the epitome of Web-enabled authorship wherein they 
can exercise enormous agency. The completion of the Facebook profile, insofar as defining one's presence on social networks, indicates how much individuals want to construct one's full identity on Facebook. Previous studies have found that individuals report higher self-esteem when they make changes to their online profiles, because of heightened self-awareness and self-presentation [21].

Based on the preceding review of theoretical and empirical work, we propose the following hypotheses for study in the SNS context:

H3: The higher the sense of agency for individuals, the higher the level of profile completion on Facebook.

H4: The higher the level of self-monitoring, the greater the frequency of wall customization in Facebook.

\subsection{Facebook as Personal Identity vs. Social Identity}

Facebook affords the ability to portray oneself in the best possible light. By either monitoring the Facebook wall or customizing the presentation on Facebook, users can carefully mold one's online identity. However, no matter how changeable an identity could be in Facebook, the original characteristic in oneself would still be the determining factor in one's online identity. In other words, although users of Facebook tend to create certain forms of online identity for themselves and are allowed more liberty to shape it than in the offline world, they still operate within the constraints of their original offline identity. The relationship between online identity and offline identity is bidirectional and mediated by a host of psychological factors and behaviors.

In general, identity, conceptualized by previous researchers as "an individual's perception of selfhood," contains two basic facets [22, 23]. One focuses on individuals' self-consciousness and self-reflection. The other facet, labeled "social identity," goes one step further by paying attention to personal behaviors within a group or public context [24]. Different from the personal identity, which is based on personal accomplishment and material attainment, social identity becomes a matter of impression management, directed at motivating others to achieve and maintain positive concepts of oneself in public [25, 26].

Empirical studies have confirmed the direct relationships between different types of Facebook user behaviors and their identity. DiMicco and Millen [27] conducted a survey based on the Facebook profiles visible when browsing IBM's network to examine the relationship between a Facebook users' profile behaviors and their online identities. They found that individuals use different profile pages in order to maintain multiple self-identities on Facebook. Ellison et al. [28] showed that people with low self-esteem gained more social capital, which can strengthen their social identity through Facebook if they update their wall more intensely. Basically, what individuals "invest" in "who they are" allows them to reconfirm the personal identity facet inside one's selfhood; while what they "invest" in "who they are communicating with" leads them to awaken the social identity component inside them.

Thus, under this line of reasoning, it is to be expected that identity, perceived by individuals within the context of Facebook, will also contain two dimensions 
determined by selfhood and self-esteem. Specifically, we propose that the "I"dominated high self-esteem will connect to personal identity while the "Me"influenced low self-esteem will relate to social identity. Based on this rationale, we hypothesize,

H5. The higher the level of profile completion on Facebook, the higher the degree of perceived personal identity from Facebook.

H6. The greater the frequency with which individuals customize their Facebook wall, the higher their degree of perceived social identity from Facebook.

\subsection{Identity and Virtual Possession}

If indeed our online activities can shape our identity, the products of those activities (the conversation threads archived, the digital images tagged, and so on) are likely to become treasured "virtual possessions". Given the increasing amount of time and resources spent on social networking and other online activities, we are entering the realm of "real virtuality," wherein the mediated world is a major aspect of our everyday "reality" [29]. The boundary between material possessions and virtual possessions is now blurring. Odom and his colleagues define virtual possessions as "artifacts that are increasingly becoming intangible (i.e. books, photos, music) and things that have never been traditionally considered as tangible goods, (i.e., SMS archives, social networking profiles)" ([30], p. 1491).

Facebook provides individuals with specific, virtual information wherein users benefit from a sense of oneself. In the present study, we suggest that Facebook acts as a virtual container of online social information (about oneself) that may be considered as "virtual possessions" by its users. Given this, it is necessary to analyze the factors that impact the role of one's own network on Facebook as a virtual possession and how we value this possession.

Any possession is based on attachment with certain specific meanings. As Odom et al. note, a possession should have its value in either fulfilling one's life or helping establish an idealized future goal [30-32]. Researchers argue that individuals form a meaningful attachment toward possessions through the process of self-extension [33]. Therein, lessons learned about possession-attachment develop and form a template (internal working model) on which relationships are built for life, which is relatively close to self-concept and self-identity. By mapping these mechanisms from material possession constructs, the following hypotheses can be posited about the relationship between online identity and virtual possessions.

H7: The higher the degree of personal identity perceived from Facebook by individuals, the higher the value they place on Facebook as a virtual possession.

H8: The higher the degree of social identity perceived from Facebook by individuals, the higher the value they place on Facebook as a virtual possession.

Taken together, a hypothetical structural model is proposed to predict how psychological differences of Facebook users affects their valuation of virtual possessions by examining different types of Facebook user behaviors, leading to different attitude outcomes pertaining to their personal and social identity (See Fig. 1). A person's selfesteem is expected to positively predict their sense of agency, which in turn is 
associated with more Facebook profile behavior and a higher degree of personal identity perceived in Facebook. On the other hand, self-esteem is expected to negatively predict the level of self-monitoring, which is associated with more Facebook wall customization and a higher degree of social identity perceived in Facebook. Both personal identity and social identity derived from Facebook are said to predict the value that users place on Facebook as a virtual possession.

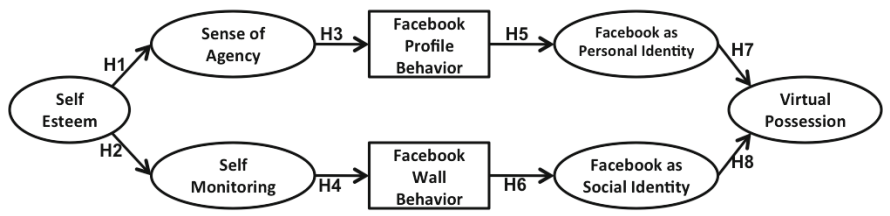

Fig. 1. Hypothesized Model

\section{$3 \quad$ Method}

\subsection{Procedure}

An online survey was conducted in spring, 2012 to test the hypotheses in this model. Participants from a Korean University were recruited for this study by posting the survey link on the school community website, with an offer of 2000 won as compensation for participation. A total of 225 participants using Facebook produced usable responses. Respondents were 51\% female, $61.5 \%$ used the original Facebook interface (while the rest used the timeline-based interface, which was introduced shortly before our data collection began), and the average age was 22.2 years.

On the first page of the study, participants were informed that they were participating in an investigation of individuals' Facebook usage. All participants were offered an informed consent form and a pre-knowledge question prior to their participation. Respondents were given the sample picture of the two types of Facebook interfaceoriginal interface and timeline interface. They were asked to choose the Facebook interface that they are currently using. Upon consenting with a click, they were directed to the corresponding questionnaire.

Before launch of the study, we pretested the entire questionnaire with 24 students (14 females and 10 males) from the same Korean university, who were also paid 2000 won for their participation. Based on the insights gained from the pretest, we were able to prepare the final version of the questionnaire by modifying and adding some items, especially questions about Facebook use behaviors.

\subsection{Measurement}

According to Facebook user menu and pretest results, we operationalized user behaviors on Facebook profile as "the degree of completing the profile fields" and Facebook wall behaviors as "the frequency with which users customized their Facebook wall." Respondents were asked to log into their Facebook account and answer the 
questions based on what they saw on their Facebook profile and wall. In the Facebook profile section, 33 categories were listed for measuring their profile behavior, such as "work", "relationship", "family", etc. Participants were asked to answer whether they have filled in those fields or not by selecting "yes" or "no". The number of categories that were indicated as "yes" was summed up as a continuous measure for "Facebook Profile Behavior" $(M=12.72, S D=6.58)$. For the Facebook wall section, due to different functions provided in the timeline interface and the original interface, we chose the common items across the two interfaces. Specifically the customizable items are "change friend list", "delete posts", "change date", and "add position". The frequency for the four items was measured by using 0-7 scale $(0=$ Never, $7=$ daily $)$. The mean value of the four items was calculated as the value for Facebook wall behavior $(M=2.69, S D=1.31)$.

In order to measure individual's level of self-esteem, six items were adopted from the Rosenberg Self-Esteem Scale [34], including "I feel that I'm a person of worth, at least on an equal plane with others", "I have a bunch of friends that care about me", and so on (Cronbach's $\alpha=.81$ ). Responses were reported on a 7-point Likert scale with higher scores indicating higher self-esteem.

Sense of agency was measured via nine items based on Kim \& Sundar [35]. These items consisted of "I feel that I can control my destiny", "I feel like I can exercise my free will", "I feel like I can access information that is appropriate for me", and so on. These items were measured using a 1-7 scale, ranging from strongly disagree to strongly agree (Cronbach's $\alpha=.86$ ).

The Self-Monitoring scale has proven useful in measuring individuals' sensitivity to social presentation [36]. However, given the present study's focus on presenting oneself in the most positive light to others and based on psychometric data about the scale from past studies, six questions were adapted from the Other-Directedness Factor of the Self-Monitoring Scale [37]. Example items include "In different situations and with different people, I often act like very different persons", "In order to get along and be liked, I tend to be what people expect me to be rather than anything else", and so on. These items were measured using a 1-7 scale, ranging from strongly disagree to strongly agree. The ratings across the six items were averaged to yield the "Self-monitoring" index (Cronbach' $\alpha=.75$ ).

We selected four items capturing the degree of public attachment from Ball and Tasaki's nine-item scale and revised them to reflect the participant's relationship with Facebook (e.g., "If someone hacked my Facebook page, I would feel like I have been personally attacked," etc.) [38]. The questions loaded under the factor labeled "Facebook as Social identity" (Cronbach's $\alpha=.68$ ).

As we suggested, the emotional significance of one's Facebook profile would strengthen the personal facet of attachment. Therefore, an amended version of the Possession-Self link Scale [39] was adopted to measure the personal identity derived from Facebook. The answers to these questions were recorded on a 7-point Likert scale with a higher score indicating greater degree of perceived personal identity from Facebook. Reliability among the five items (e.g., "Facebook has helped shape my 
identity", "Facebook has helped me narrow the gap between what I am and what I try to be", etc.) was high (Cronbach's $\alpha=.90)$.

To yield the Virtual Possession index, five questions were created to capture the degree to which participants value Facebook. The monetary value relating to a social networking site as virtual possession was measured by the following items: "I don't care if all my data on Facebook is transferred to another website (Reverse)", "I would like to pay to add music on my Facebook", "If Facebook starts selling Facebook Emoticons, I am willing to pay for it", "If Facebook starts selling Facebook Wall paper, I am willing to pay for it", and "If Facebook starts selling Facebook Wall themes I am willing to pay for it" (Cronbach's $\alpha=.71$ ).

In order to control for potentially confounding factors, individual demographic questions were asked (e.g., age, gender, grade, etc.). The Facebook Use Intensity Scale [28] was also used to control individual differences in Facebook use behavior as well as virtual possession attachment (e.g., "Facebook is part of my everyday activity", "Facebook has become part of my daily routine"). The six questions were asked on a 1-7 scale, with 1 representing strongly disagree and 7 representing strongly agree (Cronbach's $\alpha=.80$ ).

\subsection{Model Specification}

Structural equation modeling (SEM) using AMOS 18.0 was used to test the hypothesized model. The hypothesized model estimated the extent to which individual differences on self-esteem predict their values on Facebook as a virtual possession, by identifying two different paths based on the theoretical discussion of the psychological differences of self concept on "Me" versus "I"-focused psychological characteristics and behaviors. One path was concerned with the concepts of sense of agency and Facebook profile behavior while the other one pertained to self monitoring and Facebook wall customization activity (see Fig. 1). Self-esteem was entered as the lone exogenous variable, with the two psychological variables (sense of agency, selfmonitoring), Facebook use behaviors (profile behavior, wall behavior) and their attitude outcomes (Facebook as personal identity, Facebook as social identity), as well as the valuation of Facebook as a virtual possession, serving as endogenous variables.

\subsection{Model Fit Indices}

This study followed the indicators provided in AMOS to assess the overall model fit, including chi-square $(\chi 2)$, the root mean square error of approximation (RMSEA), the goodness of fit index (GFI), the standardized root mean square residual (SRMR) and comparative fit index (CFI). Considering the fact that the chi-square test is sensitive to sample size [40], the other fit indices were consulted for determining the degree to which the data fit the hypothesized model. 


\section{$4 \quad$ Results}

\subsection{Preliminary Analysis}

The data were checked for normality and outliers before the analyses. Based on the Mahalanobis distance criterion, four cases were identified as multivariate outliers and therefore removed from the dataset. As a result, the final sample size was 221. Using Kline's guideline for univariate normality, where an absolute value of less than 3.0 for skewness and 10.0 for kurtosis are considered normal, all variables in the model were normal [41]. In addition, multivariate normality was checked. The criterion for multivariate normality is that the Mardia's coefficient should be lower than $p(p+2)$, where $p$ is the number of observed variables [42]. The Mardia's coefficient for the current study was 150.06 . Given that we had 25 observed variables, we can conclude multivariate normality.

Table 1. Correlations and descriptive statistics for all measured variables

\begin{tabular}{|c|c|c|c|c|c|c|c|c|}
\hline & 1 & 2 & 3 & 4 & 5 & 6 & 7 & 8 \\
\hline 1. Self-esteem & 1 & & & & & & & \\
\hline $\begin{array}{l}\text { 2. Sense of } \\
\text { Agency }\end{array}$ & $.693 * *$ & 1 & & & & & & \\
\hline $\begin{array}{l}\text { 3. Self- } \\
\text { monitoring }\end{array}$ & $-.155^{*}$ & -.078 & 1 & & & & & \\
\hline $\begin{array}{l}\text { 4. FB as Person- } \\
\text { al Identity }\end{array}$ & -.028 & $.178 * *$ & .010 & 1 & & & & \\
\hline $\begin{array}{l}\text { 5. FB as Social } \\
\text { Identity }\end{array}$ & $.247 * *$ & $.323 * *$ & .088 & $.431 * *$ & 1 & & & \\
\hline $\begin{array}{l}\text { 6. FB as Virtual } \\
\text { Possession }\end{array}$ & $-.182 * *$ & .064 & -.030 & $.524 * *$ & $.153 *$ & 1 & & \\
\hline $\begin{array}{l}\text { 7. FB Profile } \\
\text { Behavior }\end{array}$ & .040 & .081 & .040 & $.245^{* * *}$ & -.020 & $.183 * *$ & 1 & \\
\hline $\begin{array}{l}\text { 8. FB Wall } \\
\text { Behavior }\end{array}$ & -.116 & -.076 & .073 & $.220 * *$ & .055 & $.243 * *$ & $.325^{* *}$ & 1 \\
\hline $\mathrm{M}$ & 5.44 & 4.88 & 4.19 & 3.29 & 4.60 & 2.69 & 12.72 & 2.61 \\
\hline SD & .99 & .95 & 1.12 & 1.29 & 1.15 & 1.09 & 6.58 & 1.27 \\
\hline
\end{tabular}

Note: **. Correlation is significant at the 0.01 level (2-tailed).

*. Correlation is significant at the 0.05 level (2-tailed).

Before fitting the hypothesized model, a confirmatory factor analysis (CFA) was performed to verify the factor structure of the observed variables in the model. The model fit was poor according to the following indices in CFA: $\chi 2=1782.405$, $\mathrm{df}=838, p<.001 ; \mathrm{RMSEA}=.072(\mathrm{CI}=.067-.076)$; CFI $=.837$; GFI $=.716$. Two items from 'Self-esteem', five items from 'Sense of Agency' and two items from 'Self-monitoring' variable were iteratively removed from the dataset because they were not significantly correlated with and/or had low factor loadings on their respective latent constructs. After eliminating these items, fit indices improved: $\chi 2=699.507$, $\mathrm{df}=384, p<.001 ; \mathrm{RMSEA}=.061(\mathrm{CI}=.054-.068) ; \mathrm{CFI}=.918 ; \mathrm{GFI}=.825$. 
Furthermore, modification indices suggested allowing the following three pairs of error terms from 'Facebook as Personal Identity' and a pair of error terms from 'Selfesteem' and 'sense of agency' to covary: (1) "Facebook has helped shape my identity" with "Facebook has helped me narrow the gap between what I am and what I try to be"; (2) "Facebook has helped me narrow the gap between what I am and what I try to be" with "My Facebook page is part of who I am"; (3) "My Facebook page is part of who I am" with "I derive some of my personal identity from my Facebook page"; (4) "I have a distinct identity" with "I feel that I can control my destiny"; (5) "I take a positive attitude toward myself" with "On the whole, I am satisfied with myself". Finally, the revised model had an acceptable fit: $\chi 2=363.999$, df $=255$, $p<.001 ; \mathrm{RMSEA}=.044(\mathrm{CI}=.033-.054)$; CFI $=.965 ; \mathrm{GFI}=.885$.

Based on the result of the CFA, reliability for each construct was evaluated with the remaining items. In order to test the interrelationships among the constructs in the model, the reliability (Cronbach's alpha) and the zero-order correlations were computed (see Table 1). Most of these bivariate correlations were significant and in a direction that was consistent with the hypotheses.

\subsection{Testing the Hypothesized Model}

To test the hypothesized model, SEM was conducted with the maximum likelihood estimation method. The result showed that the overall model was a reasonable fit in terms of RMSEA and CFI, but not SRMR and GFI: $\chi 2=591.125, \mathrm{df}=314, p<.001$; RMSEA $=.063(90 \%$ CI: $.055-.071)$; CFI $=.912 ;$ SRMR $=.1166 ;$ GFI $=.842$. Therefore, model modifications were conducted based on theoretical rationale and modification indices.

First, a pathway from 'Facebook wall behavior' to 'Facebook as Social Identity (FASI)' ( $\beta=0.085, p=.288$ ) was detected as non-significant. Owing to the fact that the study failed to support this originally hypothesized path, and considering the fact that 'FASI' holds no theoretical value as an independent exogenous variable, this latent construct was removed from the model entirely. After the deletion of 'FASI', overall model fit improved: $\chi 2=400.537, \mathrm{df}=244, p<.001$; RMSEA $=.054(90 \%$ CI: $.044-.063)$; CFI $=.947$; SRMR $=.0852 ; \mathrm{GFI}=.869$. Yet, the fit of this model hovered around acceptable criteria.

After considering the modification indices and based on theoretical rationale, a path from 'Facebook wall behavior' to 'Facebook profile behavior' was added to the model. The change resulted in the following fit statistics: $\chi 2=370.213, \mathrm{df}=243, p<$ .001 ; RMSEA = .049 (90\% CI: .039 - .059); CFI = .957; SRMR = .0782; GFI = .877. Since 'FASI' was removed, the direct path from 'Facebook wall behavior' to 'Facebook as Personal Identity (FAPI)' was suggested by the modification indices. The data suggest that the more Facebook users engage in customization activities on the wall, the greater the sense of personal identity perceived from Facebook, instead of a sense of social identity. From a theoretical perspective, customization of the wall is likely to be associated with personal identity according to the agency model of customization [2]. After adding the path from 'Facebook wall behavior' to 'FAPI', the overall model fit improved to a respectable level: $\chi 2=361.897$, df $=242, p<.001$; 
RMSEA = .047 (90\% CI: .037 - .057); CFI = .959; SRMR $=.0729 ;$ GFI $=.880$. Fig. 2 depicts the final model that was retained for interpretation.

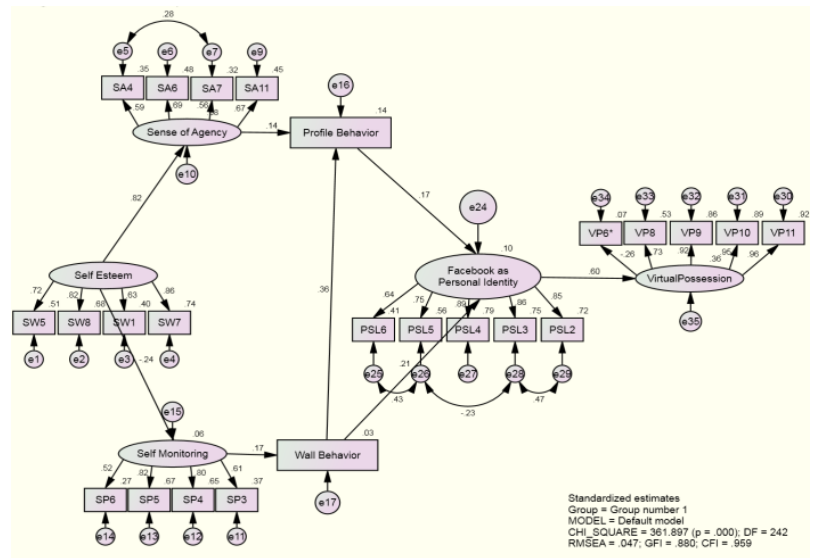

Fig. 2. Standardized path coefficients for the final model

\subsection{Summary of Findings}

The analysis showed that self-esteem has a significant positive effect on sense of agency $(\beta=.82, p<.001 ; \mathrm{H} 1)$ and a significant negative effect on self-monitoring $(\beta$ $=-.24, p<.005 ; \mathrm{H} 2)$, meaning that individuals with a higher self-esteem have a higher sense of agency, while individuals who have a lower self-esteem tend to use selfmonitoring strategy to control how they present themselves in the public $(\mathrm{H} 1, \mathrm{H} 2$ were supported). The results also suggest that self-esteem had stronger direct effects on sense of agency than on self-monitoring.

In addition, sense of agency is associated significantly with the information that was inputted in one's profile $(\beta=.14, p<.05$; H3); and the relationship between selfmonitoring and Facebook wall behavior was also statistically significant $(\beta=.17, p<$ .05 ; H4) (H3, H4 were supported). Although the variances explained by each psychological factor (sense of agency, self-monitoring) on the respective Facebook behaviors are not large, they are meaningful enough to reveal the relationships between selfesteem and the different kinds of Facebook activities by users. Furthermore, the path from Facebook wall behavior to Facebook profile behavior showed a significant relationship $(\beta=.36, p<.001)$. This means that if individuals customize their Facebook wall more frequently to promote themselves in public, they are more likely to input more information in their profiles and thereby establish a more comprehensive online presence.

More interestingly, both the profile behavior and wall behavior are significantly associated with Facebook as Personal Identity (FAPI). Thus, both the amount of information in their profile $(\beta=.17, p<.05)$ and the degree of wall customization $(\beta=.21$, $p<.05)$ are positively related to the sense of personal identity derived from Facebook 
(H5 was supported) rather than social identity (H6 was rejected). Ten percent of the variance for perceived personal identity from Facebook is accounted for by these two behaviors.

Also, results show that the higher the degree of personal identity perceived from Facebook, the higher the value of Facebook as a virtual possession for the users $(\beta=.60, p<.001)$. Therefore, $\mathrm{H} 7$ was supported. The estimated variance of virtual possession accounted for by FAPI is 0.36 .

Table 2. Estimated (Standardized \& Unstandardized) S.E. and C.R. for the supported hypothesized paths

\begin{tabular}{llllc}
\hline Paths & $\begin{array}{l}\text { Estimates } \\
\text { (Unstandardized) }\end{array}$ & $\begin{array}{l}\text { Estimates } \\
\text { (standardized) }\end{array}$ & $\begin{array}{l}\text { Standard } \\
\text { Error }\end{array}$ & $\begin{array}{l}\text { Critical } \\
\text { Ratio }\end{array}$ \\
\hline Self-monitoring <--- Self-esteem & -0.28 & -0.24 & 0.10 & -2.90 \\
FB WB<--- Self-monitoring & 0.26 & 0.17 & 0.11 & 2.27 \\
Sense of Agency <--- Self-esteem & 0.84 & 0.83 & 0.13 & 6.64 \\
FB PB <--- Sense of Agency & 0.17 & 0.14 & 0.09 & 1.95 \\
FB PB<--- FB WB & 0.25 & 0.36 & 0.04 & 5.72 \\
FAPI <--- FB PB & 0.23 & 0.17 & 0.98 & 2.33 \\
FAPI <--- FB WB & 0.20 & 0.21 & 0.70 & 2.92 \\
Virtual Possession <--- FAPI & 0.68 & 0.60 & 0.74 & 9.21 \\
\hline
\end{tabular}

Note: All of the paths were statistically significant at $p<.05$

FAPI: Facebook as Personal Identity; FB: Facebook;

WB: Wall Behavior; PB: Profile Behavior

In sum, the data show that self-esteem is positively related to sense of agency and negatively related to self-monitoring, with these psychological characteristics predicting user behavior on Facebook. We found that the more users engage in using Facebook, both for completing Facebook profile and customizing Facebook wall, the more they attached their personal identities to Facebook because both the profile and the wall end up reflecting the self. Table 2 provides an overview of the estimates, standard errors and critical ratios for the paths in the model.

\section{Discussion}

Overall, our analysis suggests, based on structural equation modeling, that the psychological factors underlying Facebook user behaviors influence the degree to which Facebook is seen as a reflection of one's personal identity and the extent to which this social-media site is valued as a virtual possession.

\subsection{The "I" vs. "Me" Paradigm in Facebook}

This study proposed two possible paradigms, the "I" and the "Me", in one's selfhood within the virtual reality of SNS. As we hypothesized, self-esteem is related to the two facets of selfhood, each associated with distinct psychological factors and 
Facebook behaviors. The sense of "I"-ness focuses on a reflection of true inner self; the sense of "Me"-ness is externally influenced, wherein one's sense of self is derived from one's public presentation. For those individuals who have the "I" oriented personality, i.e., a higher level of self-esteem, a higher sense of agency was reported; while for those individuals with a "Me" orientation and a lower level of self-esteem, a higher need for self-monitoring was noted. These psychological states are able to predict distinct user behaviors on Facebook. Individuals who perceived a higher sense of agency tend to complete their profiles with more information, showing their true self and constructing a detailed online presence. On the other hand, individuals who show a higher level of self-monitoring tend to customize their online public presentations (by altering entries in their Facebook wall) more frequently. These behaviors have implications for the design of audience awareness mechanisms. On the one hand, interface features could be designed to inform users about the number of times their profile and wall postings were viewed by others. On the other hand, a system utility can be designed to keep track of the frequency of changes to the user's profile and modifications of wall postings.

As it turns out, these two activities are related. We found that individuals who customize their Facebook wall more frequently have a higher level of profile completion. It suggests that the degree to which individuals promote themselves in public has an influence on their desire to construct a formal and complete online presence. In turn, profile behavior emerged as an important construct connecting one's self-esteem to the tendency for projecting one's online personal identity through Facebook in the final model. All this implies that users value the profile space in Facebook as an important part of their online persona construction. Therefore, design changes to Facebook profile should be geared toward affording users the ability to customize in ways that can project their personal identity.

One of the notable findings of this study is that instead of increasing a sense of social identity as hypothesized, behavior on the Facebook wall (that is presumably meant for carefully articulating one's public self-presentation) was actually positively correlated with private identity-focused attachment. While some previous research has shown that the other-directedness in self-monitoring is negatively correlated with self-focused identity building, other research has shown that self-monitoring could also be seen as self-expression rather than self-promotion [43]. Instead of simply advocating oneself, self-monitors may be more likely to use this strategy to construct a self-concentrated identity [44]. Our data suggest that, over time, users accept Facebook as part of their routine and do not see it simply as a networking tool, but rather as a venue for expressing and shaping one's self identity, be it their true self or artificial self. This has implications for Web 2.0 application design, in that greater emphasis should be placed on tools that help users shape their personal identity. Based on their online activities, individual users could be offered a personalized palette of online personas to choose from so that they can visualize how others may view them. Various framing strategies can be offered to users with the help of tools that ask users whether they want to be seen by others in this light or that way, and then proceed to identify those profile elements and wall activities that are consistent and those that are inconsistent with their chosen identity, so that users can make judgments about their own online identity as well as decisions about projecting the type of identity that they wish to present to others. 


\subsection{Personal Identity and Virtual Possession}

A statistically significant portion of the variance in perceived attachment to Facebook as personal identity can be explained by the two kinds of behaviors we examined in this study. The results indicate that Facebook successfully attracts users who create different strategies for representing themselves online and, more importantly, for expressing their true selves. As mentioned above, the present study only distinguishes two types of user behaviors on Facebook - information completion in the profile section and customization frequency in the wall section. While there are clearly many other behaviors in Facebook, we could only include those that lend themselves to counting and are explicitly recorded on Facebook, given the limitations of the selfreport survey method that we employed. Hence, it is not surprising that the variance in self-focused attachment to Facebook that is explained by the two kinds of behaviors measured in the current study is only 10 percent, but it is nevertheless a significant indicator of the behavior-attachment connection.

Even though we focused on Facebook's potential to promote both social identity and personal identity as potential predictors of users' valuation of Facebook as a virtual possession, it was clear from the data that Facebook as Personal Identity played the more important role in the model. This demonstrates how closely linked Facebook is to one's representation of self-identity and how it affects the extent to which one values Facebook. This effect differs from the public-focused self-identity that users perceive from Facebook, which failed to show a significant association with Facebook user behaviors measured in this study. In fact, compared to the frequency of wall customizing, the extent of profile completion has a greater influence on the value of Facebook as a virtual possession, through personal identity. This has important implications, as discussed in the next section.

\subsection{Value System of Virtual Possessions}

Ultimately, it appears that self-esteem is a driving force behind our SNS use, and the extent to which the SNS reflects our personal identity is indeed predictive of the extent to which we value it as a possession. If it reflects our personal identity, we are willing to pay money for purchasing accessories on Facebook. By extension, users who see a strong personal identity reflected in their Facebook environment are more likely to pay for Facebook as a service if it were to charge usage fees. This insight can be quite useful for designers of social media sites and social apps for mobile devices. To the extent these sites and apps provide affordances for users to construct and shape their personal identity, they are likely to be valued highly by users.

\subsection{Implications for Web 2.0 Applications Design and Testing}

In addition to the aforementioned design implications, our study offers insight into measuring user experience. While traditional $\mathrm{HCI}$ literature informs us how to evaluate the quality and usability of websites and applications with usability testing (assessing such constructs as ease of use, usefulness, and navigability), our study 
identifies latent attributes that affect users' loyalty and perceived value of these sites. Our results and discussion clearly show that personal identity is a significant context of use for Web 2.0, meriting greater attention from designers. The strong connection between personal identity and value of Facebook as a virtual possession indicates that the realization of personal identity should be among the quality attributes used for testing. As Orehovački [45] suggested, the methodology for evaluating the quality of social networking applications like Facebook should be extended from usability to user experience. Based on the results of our study, we recommend that personal identity, as a subjective quality, be reflected in user-experience metrics when evaluating Web 2.0 applications for design improvements.

\subsection{Limitations and Directions for Future Studies}

This study is not without the usual limitations of exploratory research. First of all, because this study examines the value placed on virtual possessions, with some of them in monetary terms, a more heterogeneous sample - rather than the convenient college group used-is needed to predict users' valuation of SNS as a virtual possession. Second, this survey-based study also suffered from specific disadvantages due to the self-reported responses, especially for questions about specific behavior frequency and situations. Participants may have forgotten pertinent details. Furthermore, as mentioned above, this study did not capture all the categories of Facebook behaviors. It would certainly be interesting to study other categories of Facebook user behaviors such as frequency of profile photo updating and type of privacy setting. In addition, the current study only examined variables in the context of Facebook. For further studies, different SNS services could be used for testing the theoretical model.

Despite these limitations, the current study marks an important step in developing a psychological model about self-esteem and self-identity that involves both the antecedents and the consequences of Facebook user behaviors. Implications for SNS owners and advertisers may be derived from the results. For example, designers could consider all the ways in which they can enable users to build their true selves on SNS because a strong personal identity can result in greater attachment and valuation. Advertisers and social media marketers who can leverage the affordances of Facebook to offer users novel and creative opportunities to construct and exhibit their personal identity are likely to be valued more highly than their counterparts who simply focus on exposing Facebook users to their commercial appeals. Likewise, SNS groups that appeal to users' personal identities are likely to garner more support and following, especially when these groups appear as an integral part of one's profile on Facebook.

\section{Conclusion}

Social networking technology has opened up numerous possibilities for ideal selfpresentation, which not only helps us realize our individual identity but also shapes our public persona. On Facebook, we customize our wall from time to time by deleting unwanted posts or choosing to experience different levels of interpersonal 
relationships with different individuals. As shown by our second (and final wellfitting) model, the lower one's self-esteem, the higher the possibility that one will adopt the self-monitoring strategy of camouflaging one's true self. However, our data also suggest that these strategies are not simply adopted to create a perfect social identity, but to articulate one's own ideal self-identity [46].

While some scholars (e.g., [29]) argue that technology is diminishing our true selves by encouraging us to constantly seek attention from others, our data suggest that College-age users view SNS technology as an extension of oneself, not a substitute. Individuals still possess a strong eagerness to define their individual identity and to control their own feelings in a social networking environment, especially when they have a high sense of self-esteem. The eagerness to have a full online presence seems to be stronger than the desire to monitor oneself in public social networks. Further, it is clear that self-esteem affects the value we place on Facebook as a virtual possession largely because we see Facebook as a vehicle for shaping and representing our personal identity. In conclusion, our valuation of Facebook as a virtual possession is largely a result of the "I" dominated selfhood rather than a "Me" dominated outlook. We value Facebook and spend so much time with it because it offers us numerous opportunities to construct, shape and reflect our personal identity, not because it allows us to project a certain social identity to members of our network. Therefore, despite all its socialness, Facebook is a deeply personal medium.

Acknowledgement. This research is supported by the Singapore National Research Foundation under its International Research Center Keio-NUS CUTE Center @ Singapore Funding Initiative and administered by the IDM Program Office.

\section{References}

1. Greenhow, C., Robelia, B.: Informal Learning and Identity Formation in Online Social Networks. Learning Media And Technology 34, 119-140 (2009)

2. Sundar, S.S.: Self as Source: Agency and Customization in Interactive Media. In: Konijn, E.A., Sonja, U., Martin, T. (eds.) Mediated Interpersonal Communication, pp. 58-74. Routledge, New York (2008)

3. Turkle, S.: Life on the Screen: Identity in the Age of the Internet. Simon \& Schuster, New York (1995)

4. Turkle, S.: The Second Self: Computers and the Human Spirit. The MIT Press, Cambridge (1985)

5. Odom, W., Zimmerman, J., Forlizzi, J.: Virtual possessions. In: Proc. of the 8th ACM Conference on Designing Interactive Systems, pp. 368-371. ACM, New York (2010)

6. Mead, G.H.: Mind, self, and society: From the Standpoint of a Social Behaviorist. University of Chicago Press, Chicago (1967)

7. Kolb, W.L.: A Critical Evaluation of Mead's "I" and "Me" Concepts. Social Forces 22(3), 291-296 (1944)

8. Pelham, B.W., Swann, W.B.: From Self-conceptions to Self-worth: on the Sources and Structure of Global Self-esteem. Journal of Personality and Social Psychology 57, 672-680 (1989) 
9. Crocker, J., Wolfe, C.T.: Contingencies of Self-worth. Psychological Review 108, 593-623 (2001)

10. Campbell, J.D., Trapnell, P.D., Heine, S.J., Katz, I.M., Lavallee, L.F., Lehman, D.R.: Selfconcept Clarity: Measurement, Personality Correlates, and Cultural Boundaries. Journal of Personality and Social Psychology 70(1), 141-156 (1996)

11. Baumeister, R.F., Campbell, J.D., Krueger, J.I., Vohs, K.D.: Does High Self-Esteem Cause Better Performance, Interpersonal Success, Happiness, or Healthier Lifestyles? Psychological Science in the Public Interest 4, 1-44 (2003)

12. Bem, D.J.: Self-perception Theory. In: Berkowitz, L. (ed.) Advances in Experimental Social Psychology, pp. 1-62. Academic Press (1972)

13. Tice, D.M.: Self-concept Change and Self-presentation: the Looking Glass Self is also a Magnifying Glass. Journal of Personality and Social Psychology 63, 435-451 (1992)

14. Judge, T.A., Erez, A., Bono, J.E., Thoresen, C.J.: Are Measures of Self-esteem, Neuroticism, Locus of Control, and Generalized Self-efficacy Indicators of a Common Core Construct? Journal of Personality and Social Psychology 83, 693-710 (2002)

15. Gallagher, I.: Philosophical Conceptions of the Self: Implications for Cognitive Science. Trends in Cognitive Sciences 4, 14-21 (2000)

16. Zarghooni, S.: A Study of Self-Presentation in Light of Facebook. Institute of Psychology, University of Oslo (2007)

17. Steinfield, C., Ellison, N.B., Lampe, C.: Social Capital, Self-esteem, and Use of Online Social Network Sites: a Longitudinal Analysis. Journal of Applied Developmental Psychology 29, 434-445 (2008)

18. Manis, J.G., Meltzer, B.N.: Symbolic Interaction: a Reader in Social Psychology, 3rd edn. Allyn and Bacon, Inc., Boston (1978)

19. Goffman, E.: The Presentation of Self to Others. In: Manis, J.G., Meltzer, B.N. (eds.) Symbolic Interaction: A Reader in Social Psychology, pp. 171-178. Allyn and Bacon, Inc., Boston (1978)

20. Ellison, N.: Facebook Use on Campus: A Social Capital Perspective on Social Network Sites. In: ECAR Symposium, Boca Raton, FL (2007)

21. Gonzales, A.L., Hancock, J.T.: Mirror, Mirror on My Facebook Wall: Effects of Exposure to Facebook on Self-esteem. Cyberpsychology, Behavior and Social Networking 14, 79-83 (2011)

22. Bong, M., Clark, R.: Comparison between Self-concept and Self-efficacy in Academic Motivation Research. Educational Psychologist 34, 139-153 (1999)

23. Byrne, B.M.: The General/Academic Self-concept Nomological Network: A Review of Construct Validation Research. Review of Educational Research 54, 427-456 (1984)

24. Reynolds, K.J., Turner, J.C., Branscombe, N.R.: Interactionism in Personality and Social Psychology: An Integrated Approach to Understanding the Mind and Behaviour. European Journal of Personality 482, 458-482 (2010)

25. Gecas, V., Burke, P.J.: Self and Identity. Social Psychology: Sociological Perspectives on Social Psychology, pp. 41-67 (1995)

26. Hogg, M.A., Reid, S.A.: Social Identity, Self-Categorization, and the Communication of Group Norms. Communication Theory 16, 7-30 (2006)

27. DiMicco, J.M., Millen, D.R.: Identity Management: Multiple Presentations of Self in Facebook. In: The 2007 International ACM Conference on Supporting Group Work, pp. 383-386. ACM Press, New York (2007)

28. Ellison, N.B., Steinfield, C., Lampe, C.: The benefits of Facebook "friends": Social capital and college students' use of online social network sites. Journal of Computer Mediated Communication 12(4), 1143-1168 (2007) 
29. Turkle, S.: Alone Together: Why We Expect More from Technology and Less from Each Other. Basic Books (AZ), New York (2012)

30. Odom, W., Zimmerman, J., Forlizzi, J.: Teenagers and their Virtual Possessions: Design Opportunities and Issues. In: Proc. of the 2011 Annual Conference on Human Factors in Computing Systems (CHI 2011), pp. 1491-1500. ACM, New York (2011)

31. Csikszentmihalyi, M., Halton, E.: The Meaning of Things: Domestic Symbols and the Self. Cambridge University Press, Cambridge (1981)

32. Kleine, S.S., Baker, S.M.: An Integrative Review of Material Possession Attachment. Academy of Marketing Science Review 1(1), 1-39 (2004)

33. Belk, R.W.: Possessions and the Extended Self. Journal of Consumer Research 15(2), 139-168 (1988)

34. Rosenberg, M.: Society and the Adolescent Self-image, revised edn. Wesleyan University Press, Middletown CT (1989)

35. Kim, Y., Sundar, S.S.: Can Your Avatar Improve Your Health? The Impact of Avatar Attractiveness and Avatar Creation. In: Proc. of the 61st Annual Conference of the International Communication Association, Boston, MA (2011)

36. Berinsky, A.J.: Can We Talk? Self-Presentation and the Survey Response. Political Psychology 25(4), 643-659 (2004)

37. Briggs, S.R., Cheek, J.M., Buss, A.H.: An Analysis of the Self-monitoring Scale. Journal of Personality and Social Psychology 38, 679-686 (1980)

38. Ball, A.D., Tasaki, L.H.: The Role and Measurement of Attachment in Consumer Behavior. Journal of Consumer Psychology 1, 155-172 (1992)

39. Ferraro, R., Escalas, J.E., Bettman, J.R.: Our Possessions, Our Selves: Domains of Selfworth and the Possession-self Link. Journal of Consumer Psychology 21, 169-177 (2011)

40. Bentler, P.M.: Comparative Fit Indexes in Structural Models. Psychological Bulletin 107, 238-246 (1990)

41. Kline, R.B.: Principles and Practice of Structural Equation Modeling. The Guilford Press (2010)

42. Bollen, K.A.: Structural Equation Models. In: Armitage, P., Colton, T. (eds.) Encyclopedia of Biostatistics, vol. 7, pp. 4363-4372. Wiley Online Library, New York (1998)

43. Lee, S.: Psychological Effects of Culture on Aesthetic Motivation for Cosmetic Customization of Mobile Phones. PhD dissertation, The Pennsylvania State University (2011)

44. Snyder, M., Copeland, J., Giacalone, R.A., Rosenfeld, P.: Self-monitoring Processes in Organizational Settings. In: Giacalone, R.A., Rosenfeld, P. (eds.) Impression Management in the Organization, pp. 7-19. Erlbaum (1989)

45. Orehovački, T.: Development of a Methodology for Evaluating the Quality in Use of Web 2.0 Applications. In: Campos, P., Graham, N., Jorge, J., Nunes, N., Palanque, P., Winckler, M. (eds.) INTERACT 2011, Part IV. LNCS, vol. 6949, pp. 382-385. Springer, Heidelberg (2011)

46. Bargh, J.A., McKenna, K.Y.A.: The Internet and Social Life. Annual Review of Psychology 55, 573-590 (2004) 